\title{
Astragaloside IV inhibits the invasion and metastasis of SiHa cervical cancer cells via the TGF-ß31-mediated PI3K and MAPK pathways
}

\author{
LEI ZHANG ${ }^{1}$, JIE ZHOU ${ }^{1}$, XIAOKANG QIN ${ }^{2}$, HUAMING HUANG ${ }^{3}$ and CHAO NIE ${ }^{1}$ \\ ${ }^{1}$ Department of Research Office, Jiangsu Health Vocational College, Nanjing, Jiangsu 211800; \\ ${ }^{2}$ Jiangsu KeyGen Biotech Co., Ltd., Nanjing, Jiangsu 211100; ${ }^{3}$ Department of Orthopedics, \\ Xishan People's Hospital of Wuxi, Wuxi, Jiangsu 214015, P.R. China
}

Received September 10, 2018; Accepted March 4, 2019

DOI: $10.3892 /$ or.2019.7062

\begin{abstract}
Astragaloside IV is the main ingredient of the medicinal herb Radix astragali, which has reported to have antitumor activity in vitro and in vivo. To determine whether the inhibitory effect of astragaloside IV on the invasion and metastasis of the cervical cancer cells is associated with epithelial-mesenchymal transition (EMT), wound healing and Transwell assays were performed using SiHa cervical cancer cells and demonstrated that astragaloside IV inhibited invasion and migration of human SiHa cervical cancer cells in vitro. Immunocytochemical and western blot analyses indicated that astragaloside IV inhibited EMT by affecting the expression of transforming growth factor- $\beta 1$ (TGF- $\beta 1$ ) and E-cadherin in the cancer cells. Two Smad-independent pathways mediated by TGF- $\beta 1$ were identified to be associated with the effects of astragaloside IV, namely, mitogen-activated protein kinase (MAPK) and phosphatidylinositol 3 kinase (PI3K) signaling pathways. The data indicated that astragaloside IV has inhibitory effects on phosphorylation of P38 MAPK, PI3K, AKT and mTOR of SiHa cells of cervical cancer. Furthermore, MAPK and PI3K pathway inhibitors were administered to the cancer cells and the expression of E-cadherin, a marker of EMT, was determined by reverse transcription-quantitative polymerase chain reaction. The results demonstrated that MAPK and PI3K pathways were involved in the inhibitory effect of astragaloside IV on EMT. In vivo small animal imaging techniques was performed and demonstrated that astragaloside IV inhibited the metastasis of cervical cancer cells. Taken together, the findings demonstrated that astragaloside IV inhibits the invasion and migration of cervical cancer cells in vitro and in vivo.
\end{abstract}

Correspondence to: Professor Chao Nie, Department of Research Office, Jiangsu Health Vocational College, 69 Huangshanling Road, Pukou, Nanjing, Jiangsu 211800, P.R. China

E-mail: jsjknc@hotmail.com

Key words: astragaloside IV, cervical cancer, epithelial-mesenchymal transition, invasion, migration

\section{Introduction}

Cervical cancer is a common malignancy that poses a severe threat to the health of women. Each year, $\sim 500,000$ new cases of cervical cancer are diagnosed worldwide. In developed countries, the morbidity of cervical cancer has decreased as advances have been made in the diagnostic and screening methods for cervical cancer (1); however, due to the socioeconomic limitations in developing countries, cervical cancer remains one of the major causes of mortality for women in those countries (2). Therefore, identifying novel treatment options to combat cervical cancer is of the utmost importance.

Chemotherapy has a crucial role in reducing pre-operative tumor size, creating more favorable conditions for surgery and preventing post-operative recurrence and metastasis (3). It is also the primary treatment option for late-stage metastatic cervical cancer (4); however, chemotherapy also causes severe toxic effects and side effects without good therapeutic efficacy (5-7). Several active ingredients extracted from plants have been reported to be good alternatives to chemotherapeutic drugs or suitable for combined use with chemotherapeutic drugs (8).

Astragaloside IV is the main ingredient that is extracted from Radix astragali. As a small-molecule compound, astragaloside IV has antitumor efficacy and potency that are several times higher than that of astragalus extract (9-11). In vivo and in vitro data have demonstrated that astragaloside IV has anti-inflammatory and anti-viral activities that modulate the immune system. Treatment with astragaloside IV has been reported to protect and enhance cardiopulmonary function and improve the tumor microenvironment (12-15). This herb-derived active component is widely available and produces few toxic effects or side effects (16). Previous studies have demonstrated that astragaloside IV exhibits significant antitumor activity and tumor cell cytotoxic ability in vivo and in vitro (17-20).

Uncontrolled proliferation, abnormal differentiation and invasion, and metastatic capacities are among the most distinctive biological features of tumor cells (21). Epithelial-mesenchymal transition (EMT) is considered to be an important molecular mechanism associated with the 
metastasis of tumors, and has a major role in the infiltration and metastasis of malignant epithelial tumor cells (22). EMT is a process in which, under specific physiological and pathological conditions, epithelial cells are transformed into mesenchymal cells. The EMT concept was first proposed in 1982 by Greenberg and Hay (23); the study reported that lens epithelial cells formed pseudopods and had a long and narrow appearance in collagen gels. The epithelial cells differentiated into mesenchymal-like cells and exhibited increased migration and mobility (23). During EMT, microenvironmental factors are produced that act on cell receptors, inducing changes in cell signal transduction pathways. EMT is considered to be an important step in the malignant progression, invasion and migration of tumor cells. In the current study, human $\mathrm{SiHa}$ cervical cancer cells were treated with astragaloside IV, and the inhibitory effect on the invasion and migration of cervical cancer cells was evaluated. It was aimed to investigate whether the inhibitory effect of astragaloside was associated with EMT.

\section{Materials and methods}

Chemicals and reagents. Astragaloside IV (purity of $>98 \%$ as determined by high-performance liquid chromatography) was obtained from Nanjing Zelang Medical Technology Co., Ltd. (Nanjing, China; cat. no. ZL20160315021). Mitomycin C was purchased from MedChemExpress (Monmouth Junction, NJ, USA; cat. no. HY-13316-31756). A First-Strand cDNA Synthesis kit and Taq DNA Polymerase were purchased from Thermo Fisher Scientific, Inc. (Waltham, MA, USA). Matrigel was purchased from Becton, Dickinson and Company (Franklin Lakes, NJ, USA). A Transwell chambers were purchased from Corning Inc. (Corning, NY, USA). A diaminobenzidine (DAB) kit (cat. no. DAB-1031) and an EliVision plus kit (cat. no. kit-9902) were purchased from Maixin Biotech Co., Ltd (Fuzhou, China). MTT cell proliferation assay kit (cat. no. 20147849) and DMSO (cat. no. 20120322) were purchased from Jiuyi Chemical Reagent Co., Ltd. (Shanghai, China). A penicillin/streptomycin solution (cat. no. KGY002), $0.25 \%$ Trypsin-EDTA (cat. no. KGY001), western blot primary antibody diluent (cat. no. KGP106), western blot secondary antibody diluent (cat. no. KGP107), a total protein extraction kit (cat. no. KGP250), an enhance chemiluminescence detection kit (cat. no. KGP1127) and a BCA protein assay kit (cat. no. KGA902) were all purchased KeyGen Biotech Co., Ltd. (Nanjing, China).

Cell culture. SiHa cervical cancer cells were obtained from Nanjing University of Chinese Medicine (Nanjing, China). The cells were cultured in $90 \%$ Dulbecco's modified Eagle's medium $+10 \%$ calf serum complete medium (KeyGen Biotech Co., Ltd.) at $37^{\circ} \mathrm{C}$ in $5 \% \mathrm{CO}_{2}$ (volume fraction). Cells in the logarithmic growth phase were used for subsequent experiments.

MTT assay. For the MTT assay, cells were prepared at a density of $5 \times 10^{4}$ cells $/ \mathrm{ml}$, and $100 \mu \mathrm{l}$ cell suspension was seeded into each well of a 96-well plate. The cells were cultured for $24 \mathrm{~h}$ at $37^{\circ} \mathrm{C}$ in a $5 \% \mathrm{CO}_{2}$ incubator. Astragaloside IV was prepared at different concentrations $(800,400,200,100$, $50,25,12.5,6.25,3.125,1.5625$ and $0.78125 \mu \mathrm{g} / \mathrm{ml})$ using complete culture medium. To each well, $100 \mu$ l culture medium containing different concentrations of astragaloside IV was added, and the plate was incubated at $37^{\circ} \mathrm{C}$ for $24 \mathrm{~h}$. Untreated cells were the negative control group. An MTT solution was added to each well of the 96-well plate. DMSO was used to dissolve the purple formazan and optical density (OD) values were measured at $\lambda=490 \mathrm{~nm}$ (BioTek ELx800; BioTek Instruments, Inc., Winooski, VT, USA). For each group, the inhibitory rate and $50 \%$ inhibitory concentration $\left(\mathrm{IC}_{50}\right)$ values were calculated.

Wound healing assay. Cells in the log phase were trypsinized and cultured together with mitomycin $\mathrm{C}(1 \mu \mathrm{g} / \mathrm{ml})$ for $1 \mathrm{~h}$. Then, the cells were seeded in a 6-well plate at a density of $5 \times 10^{5}$ cells $/ \mathrm{ml} /$ well. Different concentrations of astragaloside IV $(800,200$ and $50 \mu \mathrm{g} / \mathrm{ml})$ prepared in serum-free medium were added. A negative control group was included. The following day, when the cells were $\sim 60 \%$ confluent, the monolayer was scratched using a sterile pipette tip. Nonadherent cells were removed by a PBS wash, the culture medium was replace, and the plate was incubated at $37^{\circ} \mathrm{C}$ for $24 \mathrm{~h}$. Subsequently, the plate was removed from the incubated, images were acquired using a light microscope (Olympus IX51; Olympus Corporation, Tokyo, Japan; magnification, $\mathrm{x} 100$ ), and cell migration was measured (Olympus IX51; Cellsens, cmactlicense 1.19; Olympus Corporation).

Transwell invasion assay. Cells in the logarithmic phase were harvested and seeded in a 6-well plate at a density of $5 \times 10^{5}$ cells $/ \mathrm{ml} /$ well. The following day, when the cells were adherent, culture medium containing different concentrations of astragaloside IV was added $(800,200$ and $50 \mu \mathrm{g} / \mathrm{ml})$. A negative control group was included. Matrigel was thawed at $4^{\circ} \mathrm{C}$ overnight and diluted 1:2 using serum-free medium. In the upper chamber of the Transwell insert, $30 \mu \mathrm{l}$ diluted Matrigel was added and at $37^{\circ} \mathrm{C}$ for $120 \mathrm{~min}$ so that the Matrigel matrix would form a gel. The cell density was adjusted to $5 \times 10^{5}$ cells $/ \mathrm{ml}$ using serum-free medium. A total of $100 \mu \mathrm{l}$ of the cell suspension was added to the Transwell chamber, and into the lower chamber, $500 \mu \mathrm{l}$ culture medium containing $20 \%$ fetal bovine serum (KeyGen Biotech Co., Ltd.) was added. The 24-well plate was cultured at $37^{\circ} \mathrm{C}$ in a $5 \% \mathrm{CO}_{2}$ incubator for $24 \mathrm{~h}$. The Matrigel and the nonmigrated cells in the upper chamber were removed using a cotton swab. The Transwell inserts were removed and inverted for air-drying for $2 \mathrm{~h}$. In a 24-well plate, $500 \mu \mathrm{l}$ culture medium containing $0.1 \%$ crystal violet was added. The Transwell inserts were placed in the culture medium, with the membrane immersed in the stain, at $37^{\circ} \mathrm{C}$ for $2 \mathrm{~h}$. After $30 \mathrm{~min}$, the membrane was removed and washed with PBS. Along the diameter of the insert, three fields of view (FOVs) were randomly selected, and images were acquired (Olympus IX51; magnification, x200). The number of cells in each FOV was counted.

Immunocytochemical detection of proteins. Cells $\left(5 \times 10^{4}\right.$ cells $\left./ \mathrm{ml}\right)$ were air dried, fixed in $4 \%$ paraformaldehyde for $30 \mathrm{~min}$ and washed with PBS three times for $3 \mathrm{~min}$ each time. Culture medium containing different concentrations of astragaloside IV was added (800, 200 and $50 \mu \mathrm{g} / \mathrm{ml})$. A negative control group was included. Two drops of a $3 \% \mathrm{H}_{2} \mathrm{O}_{2}$-methanol 
solution were added to each slide, and the slide was blocked at $20^{\circ} \mathrm{C}$ for $10 \mathrm{~min}$ and then washed three times with PBS. Next, $75 \mu 1$ goat serum (Wuhan Boster Biological Technology, Ltd., Wuhan, China) was added dropwise, and the cells were incubated at room temperature for $20 \mathrm{~min}$. Subsequently, the cells were incubated with $75 \mu \mathrm{l}$ primary antibody. The primary antibodies used were rabbit anti-human transforming growth factor- $\beta 1$ (TGF- $\beta 1$; cat. no. KG22744-2; dilution, 1:200) and rabbit anti-human E-cadherin (cat. no. KG22195-2; dilution, 1:200). Both primary antibodies were obtained from KeyGen Biotech Co., Ltd. The slides were incubated at $37^{\circ} \mathrm{C}$ in a wet box for $2 \mathrm{~min}$. After washing with PBS three times, and the cells were incubated at room temperature in a wet box for $30 \mathrm{~min}$. Then, the cells were washed three times with PBS and incubated with $50 \mu 1$ peroxidase-conjugated AffiniPure goat anti-rabbit IgG (cat. no. KGAA35; KeyGen Biotech Co., Ltd.) for $30 \mathrm{~min}$ at $37^{\circ} \mathrm{C}$, followed by three PBS washes. Then, two drops of freshly prepared DAB substrate were added to each slide. After counterstaining with hematoxylin staining solution (cat. no. D005; Nanjing Jiancheng Bioengineering Institute, Nanjing, China) for $10 \mathrm{~min}$ at $25^{\circ} \mathrm{C}$, the slides were sealed, and four areas with high expression were selected during the microscopy evaluation (Olympus IX51) to determine protein expression. Three slides were evaluated for each condition. Image Pro Plus 6.0 (Media Cybernetics, Inc., Rockville, MD, USA) was used to calculate the integral OD (IOD) over the area of the FOV. The mean density was calculated as the IOD divided by the area of the FOV.

Western blot analysis. Cells in the logarithmic growth phase were trypsinized and seeded in a 6-well plate at a density of $5 \times 10^{5}$ cells $/ \mathrm{ml} /$ well. The following day, when the cells were adherent, cell culture medium containing different concentrations of astragaloside IV was added $(800,200$ and $50 \mu \mathrm{g} / \mathrm{ml})$. A negative control group was included. For each group, $200 \mu \mathrm{l}$ precooled lysis buffer [20 nM Tris ( $\mathrm{pH} 7.5), 150 \mathrm{mM} \mathrm{NaCl}$, Triton-X-100; cat. no. KGP701; KeyGen Biotech, Co., Ltd] was added to the cells and mixed, and the cell mixture was placed in an ice bath for $30 \mathrm{~min}$. After routine vortex rotation, the cells were centrifuged for $15 \mathrm{~min}$ at $21,912.8 \mathrm{x} \mathrm{g}$ and $4^{\circ} \mathrm{C}$. The supernatants were collected, and the protein concentrations were determined using the bicinchoninic acid method. Proteins were separated by SDS-PAGE on $10 \%$ gels ( $30 \mu \mathrm{g}$ per lane) and transferred to polyvinylidene difluoride membranes, which were incubated overnight at $4{ }^{\circ} \mathrm{C}$ with $5 \%$ nonfat milk. Next, the membranes were incubated overnight with primary antibodies at $4^{\circ} \mathrm{C}$. The following primary antibodies were used: Rabbit anti-human E-cadherin (cat. no. KG22195-2; dilution, 1:200); rabbit anti-human $\mathrm{N}$-cadherin (cat. no. KG22194; dilution, 1:200); rabbit anti-human Vimentin (cat. no. KG22794; dilution, 1:200); rabbit anti-human phosphatidylinositol 3 kinase (PI3K; cat. no. KG22639; dilution, 1:500); rabbit anti-human phosphorylated (p)-PI3K (cat. no. KG22638-2; dilution, 1:500); rabbit anti-human protein kinase B (Akt; cat. no. KG21502; dilution, 1:200); rabbit anti-human p-Akt (cat. no. KG11054-2; dilution, 1:200); rabbit anti-human mammalian target of rapamycin (mTOR; Ser 2448; cat. no. KGYT2914-7; dilution, 1:200); rabbit anti-human p-mTOR (cat. no. KGYP0176-6; dilution, 1:200); rabbit anti-human extracellular signaling-regulated kinase (ERK) 1/2 (cat. no. KG30107-2;

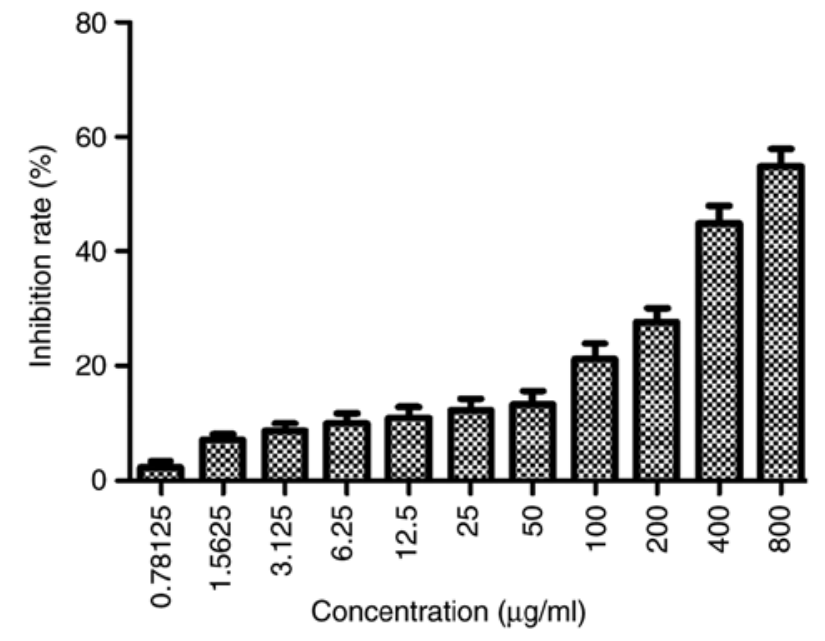

Figure 1. Inhibitory effects of different concentrations of astragaloside IV. $\mathrm{SiHa}$ cells were treated with astragaloside IV at increasing concentrations for $24 \mathrm{~h}$. The data are presented as the mean \pm standard deviation $(n=6)$.

dilution, 1:200); rabbit anti-human c-Jun N-terminal kinase (JNK) 1/2 (cat. no. KG22481-2; dilution, 1:200); rabbit anti-human P38 (cat. no. KG30244-2; dilution, 1:200); rabbit anti-human p-ERK1/2 (cat. no. KG30246-2; dilution, 1:200); rabbit anti-human p-JNK1/2 (cat. no. KG11504-2; dilution, 1:200); rabbit anti-human p-P38 (cat. no. KG11253-2; dilution, 1:200); and anti-GAPDH (cat. no. KGAA002-2; dilution, 1:200). All primary antibodies were obtained from KeyGen Biotech Co., Ltd. The membranes were washed three times with Tris-buffered saline-Tween (TBST) for $10 \mathrm{~min}$ each time and incubated with a horseradish peroxidase-conjugated goat anti-rabbit antibody (1:4,000; cat. no. KGAA35; KeyGen Biotech Co., Ltd.) for $1 \mathrm{~h}$ at $37^{\circ} \mathrm{C}$. In each of the above steps, the membrane was washed with TBST three times for 10 min each time. Images were obtained using a gel imaging system. The protein bands were visualized using ECL detection reagents (cat. no. KGP1201; KeyGen Biotech Co., Ltd.) Gray-scale analysis was performed using Gel-Pro32 software (version V4.4.0.36; Bio-Rad Laboratories, Inc., Hercules, CA, USA).

Fluorescence reverse transcription-quantitative polymerase chain reaction $(R T-q P C R)$. Total RNA extraction was performed with SiHa cells in the logarithmic phase. A sample of $5 \mu \mathrm{l}$ RNA was diluted in $495 \mu \mathrm{l} 1 \mathrm{X}$ TE buffer, and the concentration and purity of the RNA were determined according to its absorption values at 260 and $280 \mathrm{~nm}$. The extracted RNA was reverse transcribed into cDNA using a First Strand cDNA Synthesis kit (Thermo Fisher Scientific, Inc.) using the following incubation conditions: $25^{\circ} \mathrm{C}$ for $5 \mathrm{~min}, 42^{\circ} \mathrm{C}$ for $60 \mathrm{~min}$, and on ice for $5 \mathrm{~min}$. Next, qPCR was performed using a fluorescence qPCR instrument (ABI StepOne Plus; Thermo Fisher Scientific, Inc.). All primers were synthesized by GenScript (Nanjing, China) and had the following sequences: GAPDH, sense 5'-AGATCATCAGCAATGCCT CCT-3', antisense 5'-TGAGTCCTTCCACGATACCAA-3' (90 bp); E-cadherin, sense 5'-CAAGCAGCAGTACATTCT ACA-3' and antisense 5'-CATTCACATCCAGCACATCCA-3' (108 bp). GAPDH was used as an internal reference gene. The 

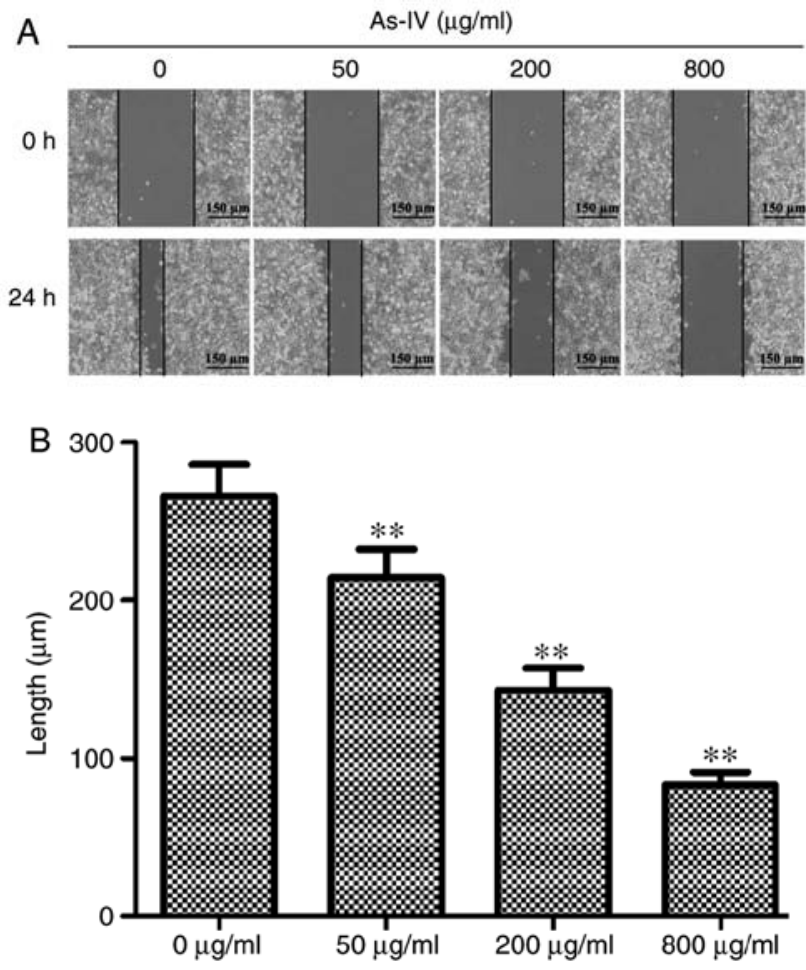

Figure 2. Inhibitory effects astragaloside IV on the migratory capacity of $\mathrm{SiHa}$ cells. (A) After the addition of different doses of astragaloside IV, the migratory capacity of SiHa cells decreased with increasing concentrations of astragaloside IV. Magnification, x100. (B) The data are presented as the mean \pm standard deviation $(\mathrm{n}=3) .{ }^{* *} \mathrm{P}<0.01$ vs. $0 \mu \mathrm{g} / \mathrm{ml}$. As-IV, astragaloside IV.

PCR conditions were as follows: Pre-denaturation at $95^{\circ} \mathrm{C}$ for $5 \mathrm{~min}$, followed by 40 cycles of denaturation at $95^{\circ} \mathrm{C}$ for $15 \mathrm{sec}$ and annealing/extension at $60^{\circ} \mathrm{C}$ for $20 \mathrm{sec}$, and denaturation at $72^{\circ} \mathrm{C}$ for $40 \mathrm{sec}$. At the end of each run, a melting curve was plotted to verify the specificity of the amplification product. Both the amplification and dissolution curves were analyzed using Rotor-Gene Real-Time Analysis Software 6.1 (Qiagen $\mathrm{GmbH}$, Hilden, Germany), and the $\Delta \Delta \mathrm{Cq}$ method was used for analysis (24). The expression of target genes was normalized to the expression of GAPDH (ABI StepOne version 2.3; Applied Biosystems; Thermo Fisher Scientific, Inc.).

In vivo imaging of tumor formation in nude mice using fluorescent probes. BABLc/nude mice were purchased from Shanghai Lingchang Biotechnology Co., Ltd. (Shanghai China). All animals were housed in a pathogen-free environment at $23^{\circ} \mathrm{C}$ with 40-70\% humidity and fed ad libitum. As $12 \mathrm{~h}$ light/dark cycle was used. The procedures for care and use of animals were approved by the Ethics Committee of the Jiangsu Health Vocational College (approval no. IACUC-201702) and all applicable institutional and governmental regulations concerning the ethical use of animals were followed. SiHa cells in the logarithmic phase were harvested, and single cell suspensions were prepared at a density of $1 \times 10^{7}$ cells $/ \mathrm{ml}$. The cells were injected subcutaneously into the right armpit at a volume of $0.1 \mathrm{ml}$ per mouse. The location of the tumors did not interfere with the normal activities of the nude mice or impair their wellbeing. The nude mice were randomly divided into four groups ( $\mathrm{n}=4$ mice per group): Control group, cisplatin group, astragaloside IV group and astragaloside IV plus cisplatin group. For the astragaloside IV group, astragaloside IV was administered by gastric lavage at a daily dose of $120 \mathrm{mg} / \mathrm{kg}$. The control group was given an equal volume of 5\% sodium carboxymethyl cellulose, whereas the cisplatin group received an intraperitoneal injection of $2 \mathrm{mg} / \mathrm{kg}$ cisplatin. Moreover, the combined treatment group received drug administration for 21 consecutive days. Biological probes, synthesized by fluorescence probe Cy 5.5 labeled epidermal growth factor, was dissolved in DMSO, prepared at a concentration of $1 \mathrm{mg} / \mathrm{ml}$ and stored at $-20^{\circ} \mathrm{C}$. At 2,4 and 6 weeks after the tumor was formed, $5 \mu \mathrm{l}$ Cy5.5 stock solution was diluted with DMSO to $0.2 \mathrm{ml}$ and injected into each mouse. At $10 \mathrm{~min}$ after injection of the fluorescent probe, the nude mice were anesthetized, and in vivo imaging was performed at an excitation wavelength of $680 \mathrm{~nm}$ (IVIS ${ }^{\circledR}$ Lumina LT Series III; PerkinElmer, Inc., Waltham, MA, USA). The experiment was terminated ENT when the volume of the tumor reached $2,000 \mathrm{~mm}^{3}$. The longest diameter of a single subcutaneous tumor was $1,954 \mathrm{~mm}$, radial width was $1,425 \mathrm{~mm}$ and the tumor volume was $1,984 \mathrm{~mm}^{3}$. Tumor volume $=1 / 2$ diameterxradial width $^{2}$.

Statistical analysis. All data are presented as the mean \pm standard deviation $(n=3)$. Statistical analyses were performed with SPSS software version 16.0 (SPSS, Inc., Chicago, IL, USA). The statistical comparisons between two groups were performed by unpaired Student's t-test and multigroup comparisons were conducted by using one-way analysis followed by the Tukey's test. $\mathrm{P}<0.05$ was considered to indicate a statistically significant difference.

\section{Results}

Astragaloside IV inhibits the proliferation of SiHa cells. SiHa cells were treated with different concentrations of astragaloside IV $(800,400,200,100,50,25,12.5,6.25,3.125,1.562$ 5 or $0.78125 \mu \mathrm{g} / \mathrm{ml}$ ) for $24 \mathrm{~h}$ (Fig. 1). The data indicated that astragaloside IV inhibited the proliferation of the cells in a dose-dependent manner. The $\mathrm{IC}_{50}$ value at $24 \mathrm{~h}$ was $628.28 \mu \mathrm{g} / \mathrm{ml}$.

Inhibitory effects of different concentrations of astragaloside IV on the migration of SiHa cells. The wound healing assay is one of the most commonly used methods to determine the migratory capacity of cells in vitro. A monolayer of $\mathrm{SiHa}$ cells was scratched in vitro, and astragaloside IV was added to determine the inhibitory effect on the migratory capacity of $\mathrm{SiHa}$ tumor cells. SiHa cells in the control group maintained the original migratory capacity, and after treatment for $24 \mathrm{~h}$, the wound distance was $96.2 \pm 4.44 \mu \mathrm{m}$. After treatment with different doses of astragaloside IV (50, 200 and $800 \mu \mathrm{g} / \mathrm{ml})$, the wound distance increased to $159 \pm 3.87,238.2 \pm 5.89$ and $296.8 \pm 6.18 \mu \mathrm{m}$, respectively, and these distances were significantly different from the wound distance of the control ( $\mathrm{P}<0.05$; Fig. 2). Thus, astragaloside IV inhibited the migratory capacity of SiHa cells.

Effect of astragaloside IV on the invasive capacity of $\mathrm{SiHa}$ cells. The Transwell assay, which measures the number of cells migrating to the lower chamber of the Transwell insert, 

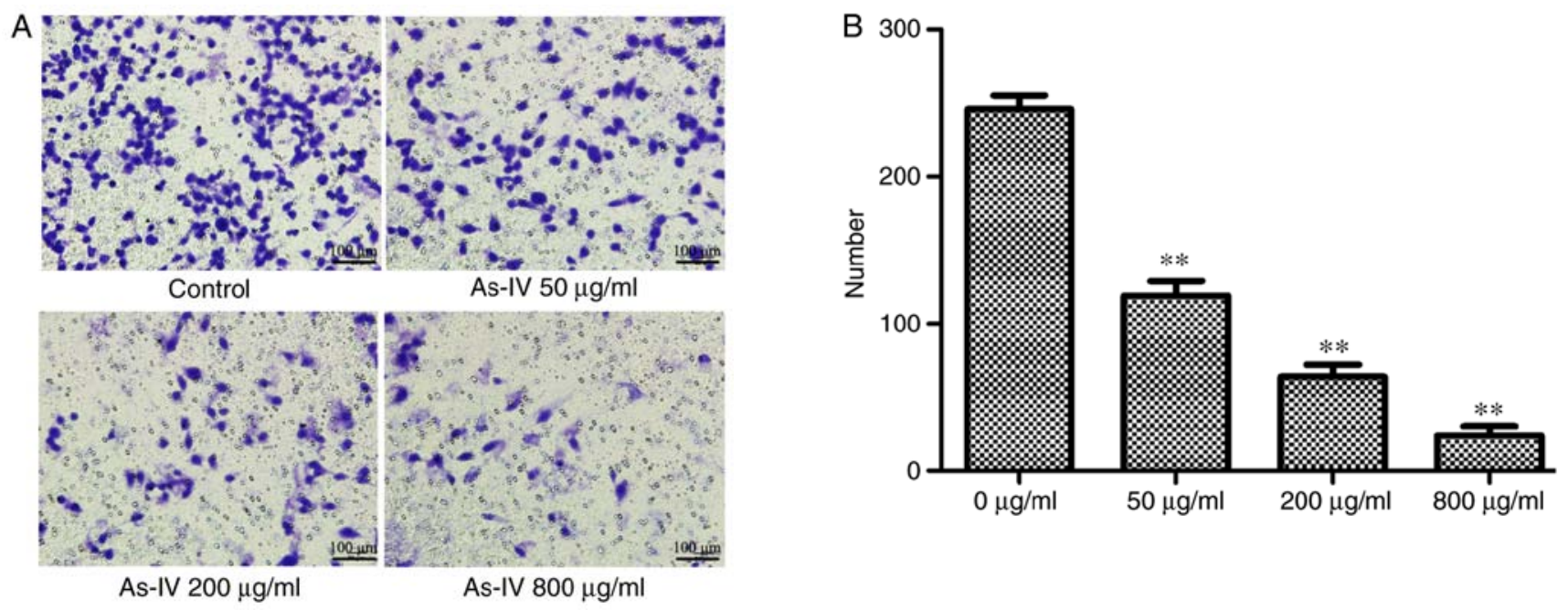

Figure 3. Inhibitory effects of different concentrations of astragaloside IV on the invasive capacity of SiHa cells. (A) The number of cells penetrating the Matrigel was assessed at $24 \mathrm{~h}$. Magnification, $\mathrm{x} 200$. (B) The data are presented as the mean \pm standard deviation $(\mathrm{n}=3){ }^{*}{ }^{*} \mathrm{P}<0.01 \mathrm{vs} .0 \mu \mathrm{g} / \mathrm{ml}$. As-IV, astragaloside IV.

\section{A a}
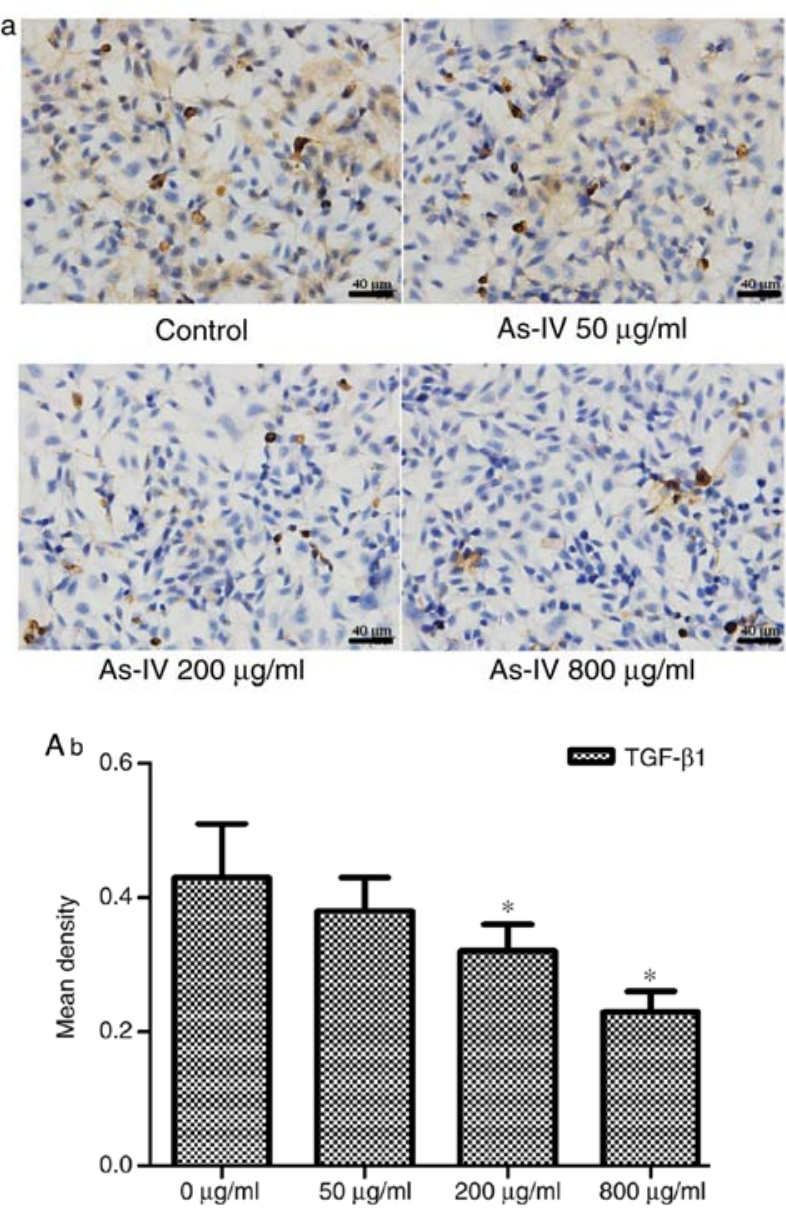

$\mathrm{Ba}$
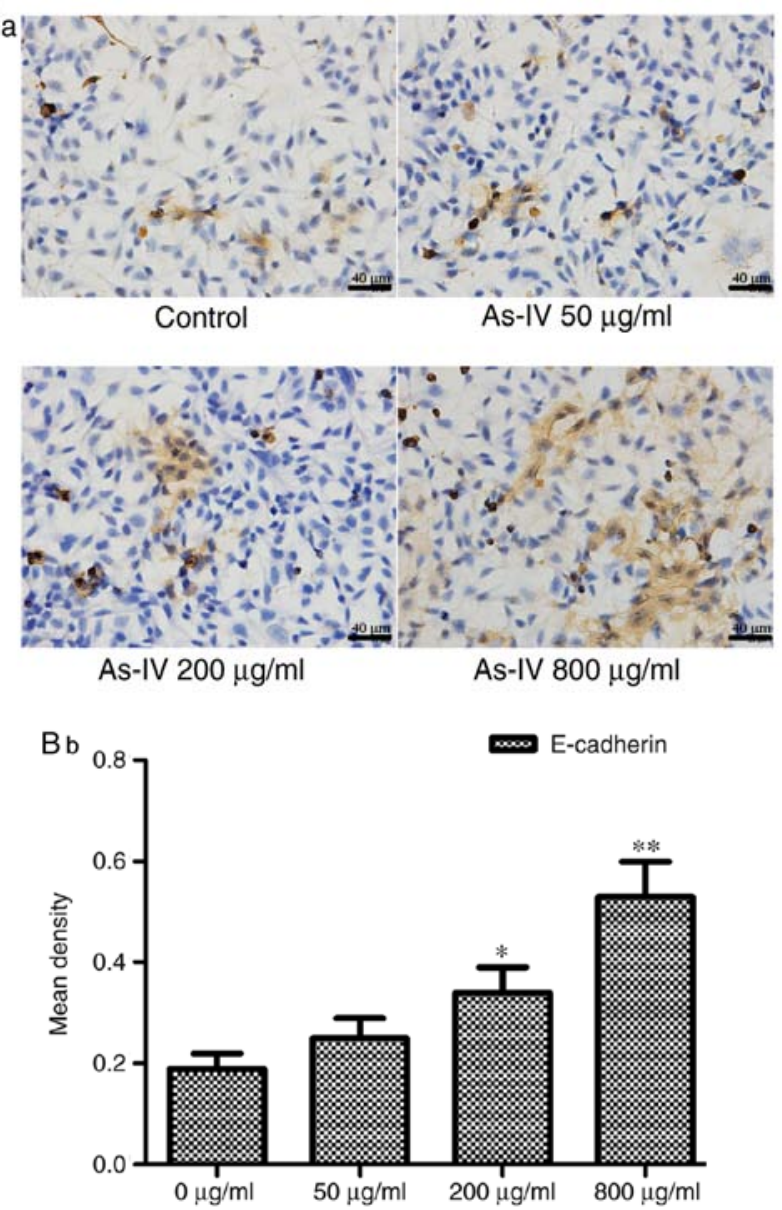

Figure 4. Expression of TGF- $\beta 1$ and E-cadherin in SiHa cells after astragaloside IV treatment measured by immunocytochemistry. TGF- $\beta 1$ and E-cadherin proteins are mainly present in the cytoplasm. The deposition of brownish-yellow particles in the cytoplasm indicated the location of the proteins. (Aa) Expression of TGF- $\beta 1$. (Ab) There were more brownish-yellow particles in the control group than the astragaloside IV groups, and the deposition decreased significantly after astragaloside IV treatment at $800 \mu \mathrm{g} / \mathrm{ml}$. (Ba) Expression of E-cadherin. (Bb) Brownish-yellow particles indicated that the positive expression of E-cadherin increased when the concentration of astragaloside IV increased. Magnification, $\mathrm{x} 200$. As-IV, astragaloside IV; TGF- $\beta 1$, transforming growth factor- $\beta 1$. ${ }^{*} \mathrm{P}<0.05$, ${ }^{* *} \mathrm{P}<0.01$ vs. $0 \mu \mathrm{g} / \mathrm{ml}$.

is a classic way to determine the invasive capacity of cells. Fig. 3 demonstrated that the number of cells migrating to the lower chamber was lower following treatment with different concentrations of astragaloside IV than in the control treatment group. In the control group, the number of cells that migrated to the lower chamber was $246.6 \pm 8.56$. However, 

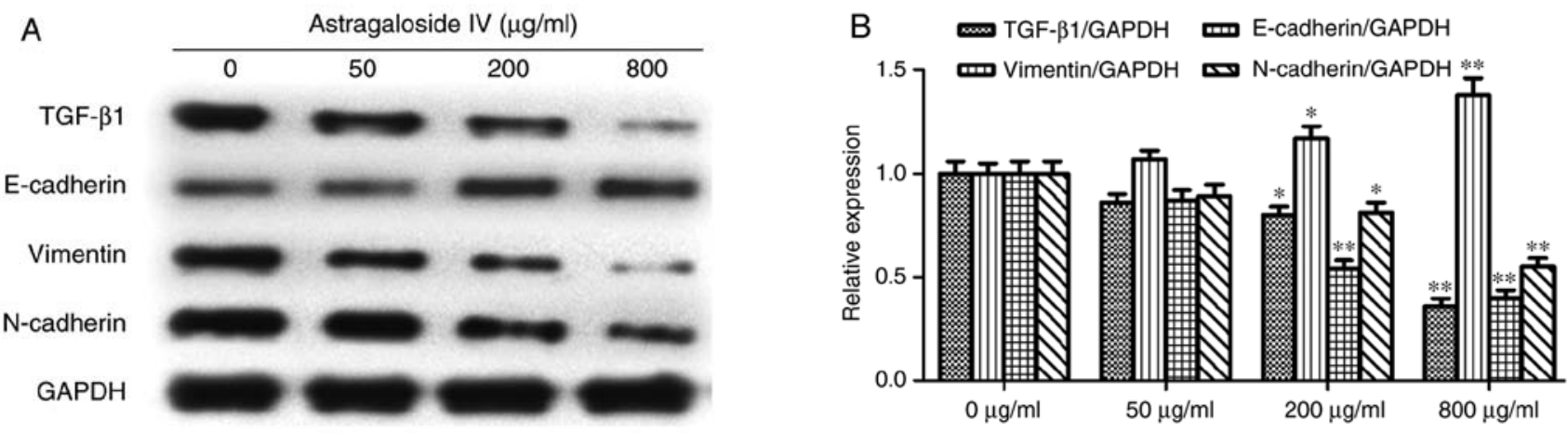

Figure 5. Expression of TGF- $\beta 1, \mathrm{~N}$-cadherin, Vimentin and E-cadherin in SiHa cells after astragaloside IV treatment. (A) Expression determined by western blot analysis and (B) densitometry semi-quantification. TGF- $\beta 1, N$-cadherin and Vimentin protein bands were darkest in the control group. When the concentration of astragaloside IV increased, the intensity of the bands decreased, indicating reduced expression of TGF- $\beta 1, N$-cadherin and Vimentin. The intensity of the E-cadherin protein band was lowest in the control group and became more intense after treatment with astragaloside IV, indicating increased expression of E-cadherin. ${ }^{*} \mathrm{P}<0.05,{ }^{* *} \mathrm{P}<0.01$ vs. $0 \mu \mathrm{g} / \mathrm{ml}$. TGF- $\beta 1$, transforming growth factor- $\beta 1$.
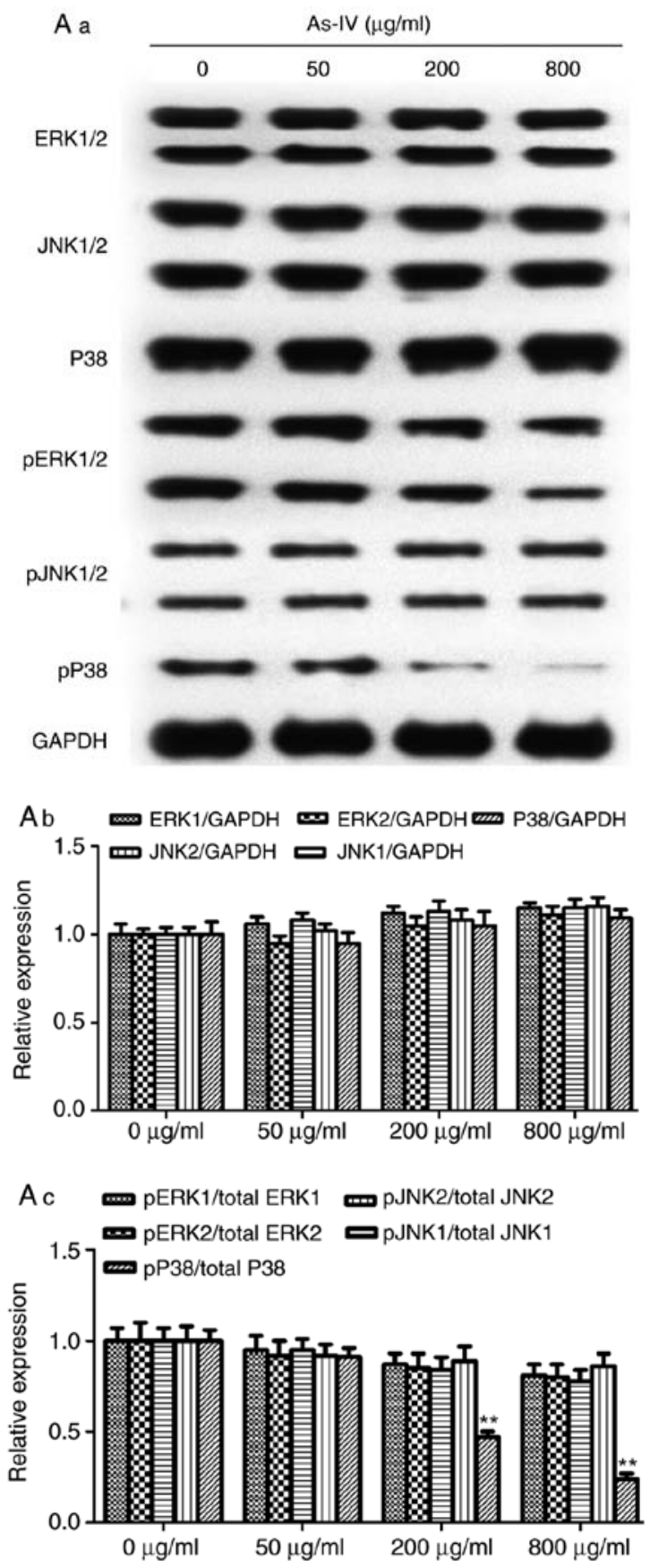
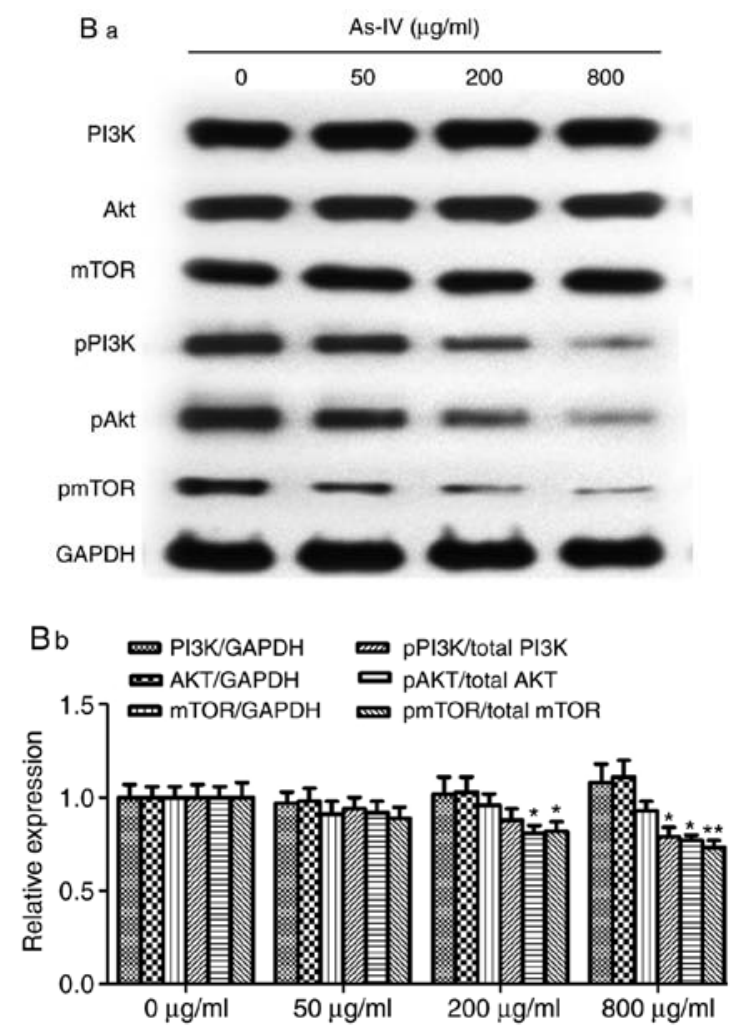

Figure 6. Effects of astragaloside IV treatment on the expression of ERK1/2, JNK1/2, P38, PI3K, AKT, mTOR and their phosphorylated forms. (Aa) ERK1/2, JNK1/2 and P38 expression determined by western blot analysis. (Ab) Densitometry analysis of total ERK1/2, JNK1/2 and P38 relative to GAPDH. (Ac) Densitometry analysis of phosphorylated ERK1/2, JNK1/2 and P38 relative to total ERK1/2, JNK1/2 and P38. (Ba) PI3K, AKT and mTOR expression determined by western blot analysis. (Bb) Densitometry analysis of total PI3K, AKT and mTOR relative to GAPDH, and phosphorylated PI3K, AKT and mTOR relative to total PI3K, AKT and mTOR. As-IV, astragaloside IV; ERK, extracellular signal-regulated kinase; JNK, c-Jun N-terminal kinase; $p$, phosphorylated; PI3K, phosphatidylinositol 3 kinase; Akt, protein kinase B; mTOR, mammalian target of rapamycin. ${ }^{*} \mathrm{P}<0.05$, ${ }^{* *} \mathrm{P}<0.01$ vs. $0 \mu \mathrm{g} / \mathrm{ml}$.

after treatment with astragaloside IV $(50,200$ and $800 \mu \mathrm{g} / \mathrm{ml})$ for $24 \mathrm{~h}$, the number of cells migrating to the lower chamber was $119.2 \pm 10.4,64.2 \pm 5.07$, and $24.8 \pm 8.7$, respectively, which indicated that compared with the control, astragaloside IV 

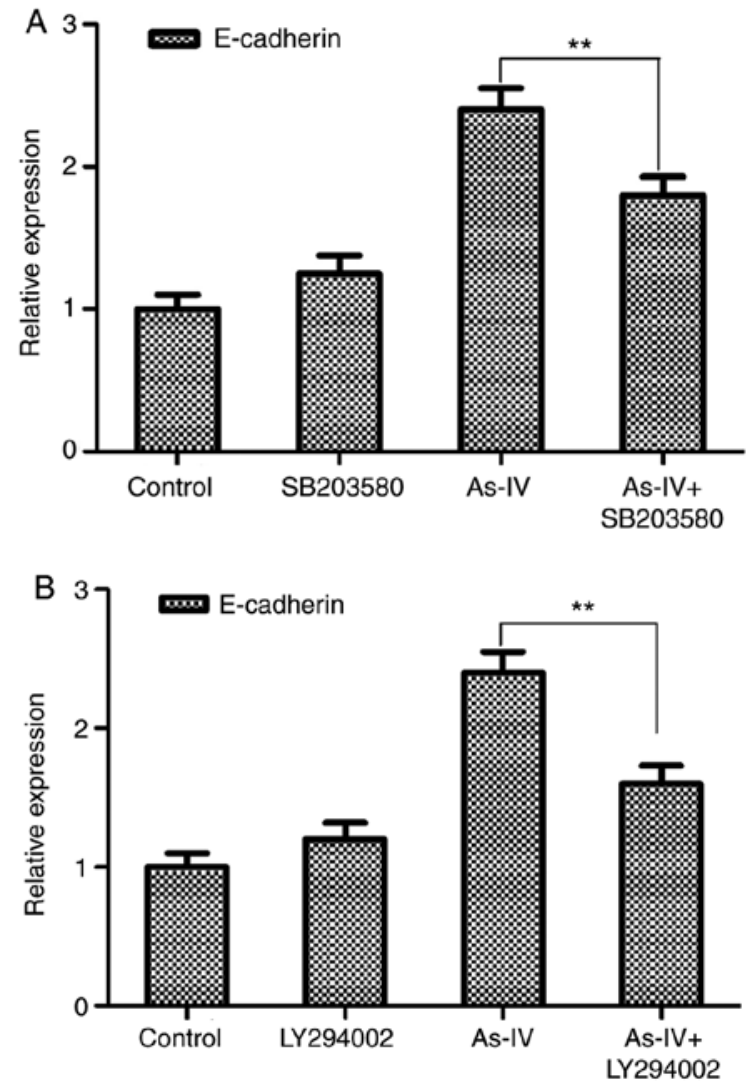

Figure 7. mRNA expression of E-cadherin measured by reverse transcription-quantitative polymerase chain reaction after use of the inhibitors SB203580 and LY294002. The changes in the mRNA expression of E-cadherin in $\mathrm{SiHa}$ cells were determined after astragaloside IV treatment $(800 \mu \mathrm{g} / \mathrm{ml})$ with (A) SB203580 $(20 \mu \mathrm{M})$ and (B) LY294002 $(20 \mu \mathrm{M})$. The data are presented as the mean \pm standard deviation $(n=3) .{ }^{* *} \mathrm{P}<0.01$. As-IV, astragaloside IV.

had a significant inhibitory effect $(\mathrm{P}<0.05)$. Astragaloside IV demonstrated a dose-dependent inhibitory effect on the invasive capacity of SiHa cells.

Effect of astragaloside IV on the expression of TGF- $\beta 1$ and E-cadherin. TGF- $\beta 1$ and E-cadherin are key markers of EMT. As shown in Fig. 4, the expression of TGF- $\beta 1$ was highest in the control group and decreased after astragaloside IV treatment. Furthermore, the expression of E-cadherin was lowest in the control group, suggesting that EMT may have occurred in the SiHa cells. After astragaloside IV treatment, the expression of E-cadherin increased. These results indicated that the inhibitory effect of astragaloside IV on the migratory and invasive capacities of $\mathrm{SiHa}$ cancer cells was associated with both proteins.

Astragaloside IV downregulates the expression of TGF- $\beta 1$, $N$-cadherin and Vimentin and upregulates the expression of E-cadherin in SiHa cells. To further determine the effects of astragaloside IV on the expression of TGF- $\beta 1, \mathrm{~N}$-cadherin, Vimentin and E-cadherin, the expression levels of the four proteins were evaluated by western blot analysis following astragaloside IV treatment. As shown in Fig. 5, TGF- $\beta 1$, $\mathrm{N}$-cadherin and Vimentin expressions were highest in the control group and decreased following astragaloside IV treatment. Furthermore, E-cadherin expression was lowest in the control group and increased in a dose-dependent manner following astragaloside IV treatment. These data suggested that astragaloside IV inhibited the invasive and migratory capacities of SiHa cells by downregulating TGF- $\beta 1, \mathrm{~N}$-cadherin and Vimentin expression, and upregulating E-cadherin expression.

Astragaloside IV inhibits the mitogen-activated protein kinase (MAPK) and PI3K signaling pathways in SiHa cells. The MAPK and PI3K signaling pathways are associated with the invasion and migration of SiHa cancer cells. The effect of astragaloside IV on these two pathways was assessed using western blot analysis. As shown in Fig. 6, astragaloside IV inhibited the phosphorylation of P38 in the MAPK signaling pathway, and phosphorylation of PI3K, Akt and mTOR in the PI3K signaling pathway in a dose-dependent manner. However, astragaloside IV had no impact on phosphorylation or expression of other proteins. Therefore, astragaloside IV inhibited certain mediators of the MAPK and PI3K pathways.

Astragaloside IV inhibits the initiation of EMT in SiHa cells via the MAPK and PI3K signaling pathways. The mRNA expression of E-cadherin was determined after the combined use of astragaloside IV, the P38 MAPK inhibitor, SB203580, and the PI3K inhibitor, LY294002. Compared with the control treatment, the use of either inhibitor alone did not significantly change the expression of E-cadherin $(\mathrm{P}>0.05)$. By contrast, combining the pathway inhibitors significantly reduced the effect of astragaloside IV on E-cadherin ( $\mathrm{P}<0.05$; Fig. 7). These data suggested that treatment with astragaloside IV inhibited EMT in SiHa cells by inhibiting the MAPK and PI3K signaling pathways.

Astragaloside IV inhibits transplanted tumor metastasis in nude mice. The findings demonstrated that compared with control treatment, astragaloside IV treatment inhibited tumor growth and migration. As shown in Fig. 8, metastasis occurred within 2 weeks in the control group and was more severe in week 6 . In the cisplatin group, tumor growth was effectively inhibited; however, extensive metastasis occurred by week 6 . Tumor metastasis was decreased in the astragaloside IV group, and only mild metastasis occurred in week 4. Furthermore, the tumor growth rate and degree of metastasis were lower in the combined treatment group than the control group. These results indicated that treatment with astragaloside IV inhibited tumor migration and invasion in vivo and in vitro. In addition, the treatment effect was strongest after combined treatment with astragaloside IV and cisplatin.

\section{Discussion}

The inhibitory effect of astragaloside IV on SiHa cells was assessed using an MTT assay, and the $\mathrm{IC}_{50}$ value at $24 \mathrm{~h}$ was calculated to be $628.28 \mu \mathrm{g} / \mathrm{ml}$. These findings indicated that astragaloside IV treatment exerted a significant inhibitory effect on SiHa cells in a dose-dependent manner. To determine whether astragaloside IV had an effect on the migratory and invasive capacities of SiHa cells, wound healing and Transwell assays were performed. The wound healing assay, which was used to determine the migratory capacity of the SiHa tumor cells, is based on the fact that tumor cells possess the capacity 
A

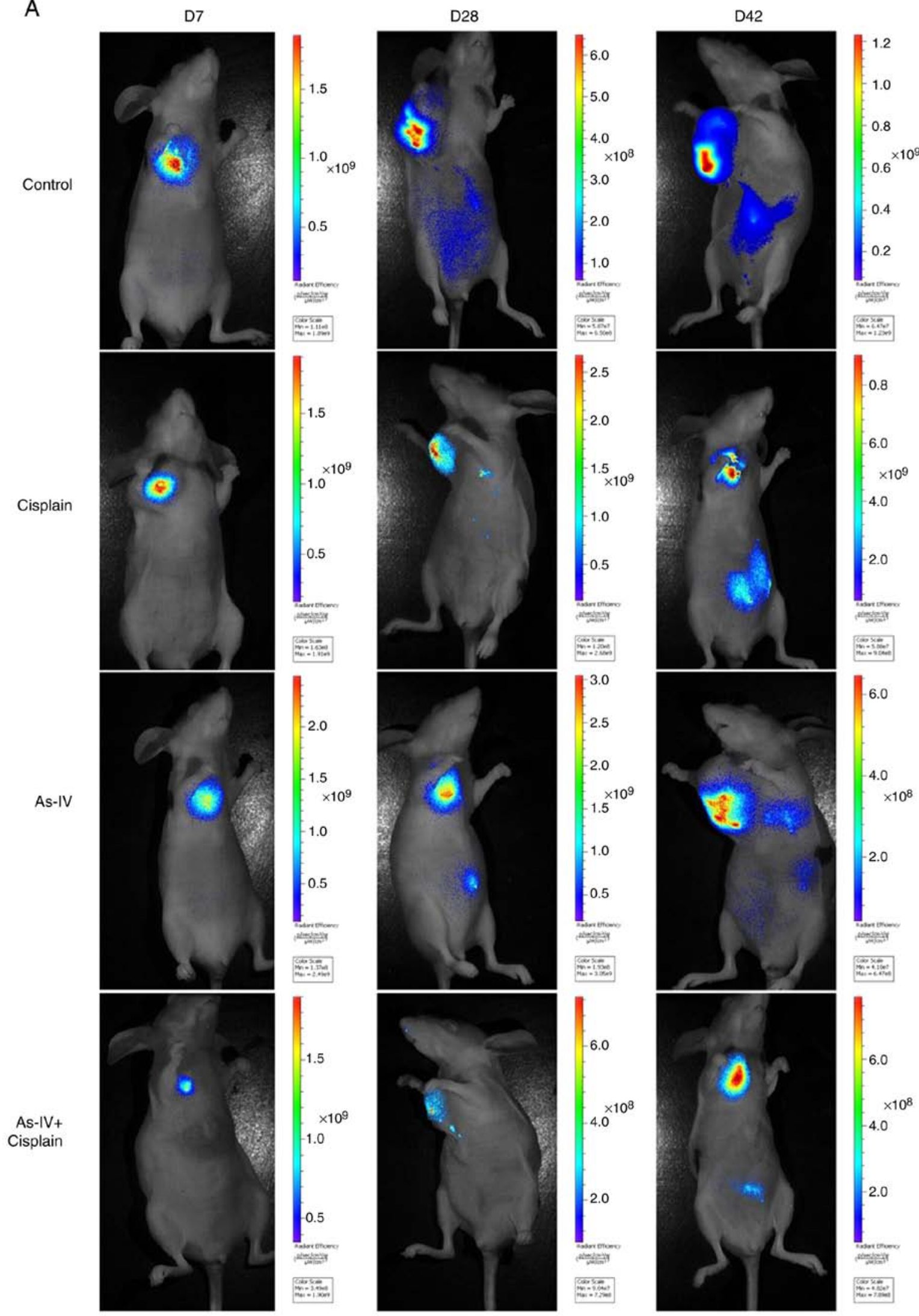

Figure 8. In vivo tumor metastasis is inhibited by astragaloside IV in nude mice. (A) In vivo fluorescence imaging was performed every two weeks for a total of 6 weeks. Representative images of the abdomen of nude mice are shown, with color indicating the regions of tumor growth and metastasis. D, day As-IV, astragaloside IV.

for migration in vitro (25). Using Transwell assays, the invasive capacity of the tumor cells was determined by counting the number of cells penetrating the Matrigel (26). Both assays are commonly used to determine the inhibitory effects of 

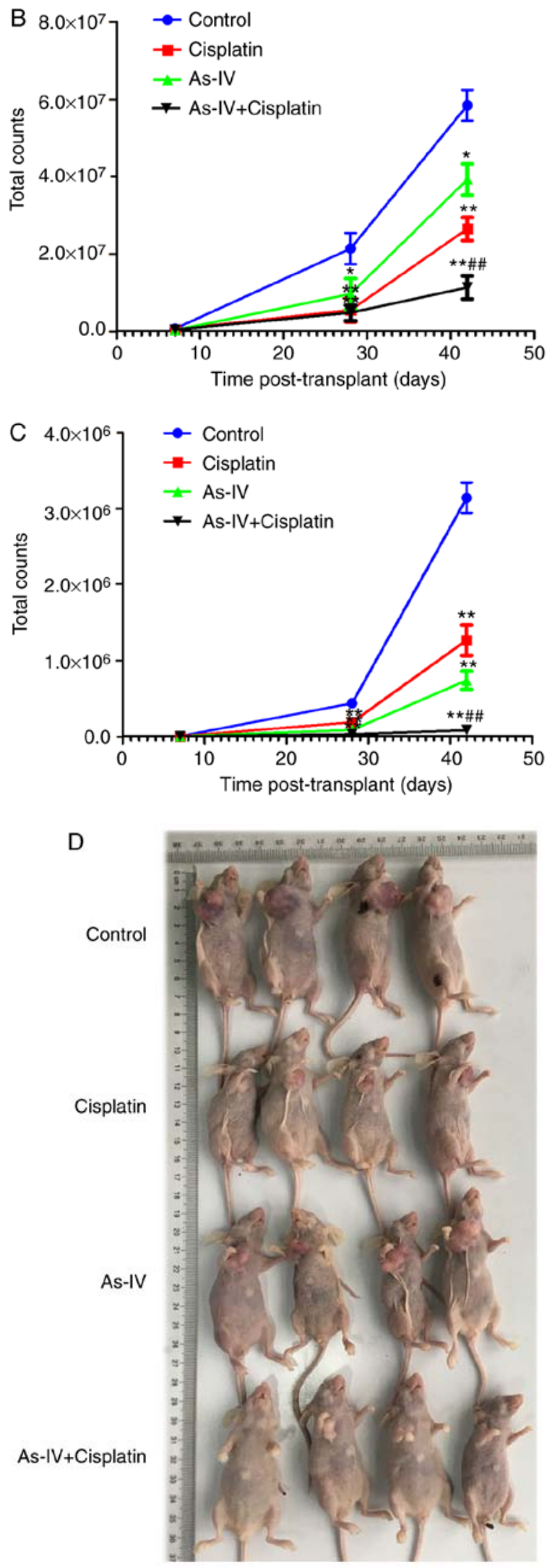

Figure 8. Continued. In vivo tumor metastasis is inhibited by astragaloside IV in nude mice. (B) Fluorescence imaging from primary tumors quantified by region of interest analysis of the images obtained on the indicated days after tumor transplantation $\left({ }^{*} \mathrm{P}<0.05,{ }^{* *} \mathrm{P}<0.01\right.$ vs. control; ${ }^{\# \#} \mathrm{P}<0.01$ vs. cisplatin). (C) Fluorescence imaging from locoregional metastatic tumors quantified by region of interest analysis of the images obtained on the indicated days after tumor transplantation $\left({ }^{*} \mathrm{P}<0.05,{ }^{* *} \mathrm{P}<0.01\right.$ vs. control; ${ }^{\# \#} \mathrm{P}<0.01$ vs. cisplatin). (D) Tumor formation in the four groups of nude mice at the end of 6 weeks. As-IV, astragaloside IV. therapeutic compounds on the migratory and invasive capacities of tumor cells (27). The migratory and invasive capacities of SiHa cells were decreased to varying extents after $24 \mathrm{~h}$ of treatment with astragaloside IV.

The major causes of cervical cancer include activation of oncogenes, inactivation of tumor suppressor genes, increased telomerase activity, and increased production of TGF- $\beta$ (28). TGF- $\beta$ is a multifunctional polypeptide molecule with the highest content of TGF- $\beta 1$. TGF- $\beta 1$ is mainly expressed in endothelial cells, hematopoietic cells and connective tissue cells $(29,30)$. TGF- $\beta 1$ is a tumor suppressor in normal epithelial cells and in the early stage of tumor development. However, in advanced tumor stages, there is a selective loss of the tumor suppressor function of TGF- $\beta 1$, which then has a role in mediating tumor cell proliferation, infiltration, and metastasis (31). During tumor proliferation, high levels of TGF- $\beta 1$ are associated with invasiveness (32). Furthermore, TGF- $\beta 1$ is an important cytokine in the tumor microenvironment, and several studies have reported that TGF- $\beta 1$ is involved in tumor EMT and promotes tumor metastasis (22,33-37). Tumor cells undergo EMT following stimulation with TGF- $\beta 1$, resulting in the transition from the paving stone-like morphology of epithelial cells to the spindle-shaped morphology of mesenchymal cells. E-cadherin has an important regulatory role in the adhesion between epithelial cells (38). Previous studies have reported that E-cadherin prevented the invasion and metastasis of histiocytes by stabilizing intercellular junctions (39). In fact, upon loss of the E-cadherin gene, epithelial cells undergo EMT in several epithelial-cell-derived cancers. This loss further enhances the invasive and migratory capacities of tumor cells (40-43). N-cadherin is a cell adhesion molecule. It participates in cell adhesion and maintains the stability of tissue structures and morphology (44). Upregulation of $\mathrm{N}$-cadherin expression in malignant epithelial tumors can reduce cell adhesion and promote the initiation of EMT (45). Vimentin is a marker of interstitial cells and an important component of the cytoskeleton. Increased abnormal expression of cytoskeleton proteins alters the composition of the cytoskeleton protein pool (46). This change makes it easier for cancer cells to migrate and invade (47).

In the current study, the expression of TGF- $\beta 1$ and E-cadherin, proteins associated with EMT, were determined in SiHa cells by immunocytochemistry following astragaloside IV treatment. The staining results indicated that treatment with astragaloside IV downregulated TGF- $\beta 1$ levels and upregulated E-cadherin levels in SiHa cells. Western blot analysis was used to determine the specific expression of the two proteins. The denistometry analysis results were in line with the immunocytochemistry results, indicating that astragaloside IV treatment inhibited the invasive and migratory capacities of SiHa cells by downregulating TGF- $\beta 1$ expression and upregulating E-cadherin expression, resulting in a reduction in EMT. Astragaloside IV can also downregulate the levels of $\mathrm{N}$-cadherin and Vimentin protein in cells. These results indicated that astragaloside IV can inhibit the initiation of EMT.

Molecular biology studies have revealed that the MAPK and PI3K signaling pathways are two important pathways in the production of TGF- $\beta 1$, and these pathways include the TGF- $\beta 1$-mediated Smad-independent pathways (48). MAPKs are a serine/threonine protein kinase family widely found in mammals. The MAPK pathway is involved in regulating cell 
proliferation and differentiation, and includes the ERK, JNK and $\mathrm{p} 38$ proteins. The kinases of this pathway can be activated by various factors (49). ERK1/2 is an important member of the MAPK family, and continuous activation of ERK1/2 following cellular stimulation promotes cell proliferation and malignant transformation. ERK can be activated by numerous factors, including TGF- $\beta 1$ and Ras. Activation of the Ras signaling pathway promotes TGF- $\beta 1$-induced EMT (50). JNK $1 / 2$ is expressed in nearly all cells in the human body. JNK can be activated by several cellular factors and oxidative injury, and ultimately acts on the caspase family via the mitochondrial pathway, thus leading to cell apoptosis. Furthermore, it has been reported that TGF- $\beta 1$ interacts with JNK, which may induce EMT (51). TGF- $\beta 1$-activated kinase 1 (TAK1) is an important MAPK kinase kinase in the TGF- $\beta 1$-activated p38MAPK pathway. TGF- $\beta 1$ activates TAK1 through the catalytic activity of TNF receptor-associated factor 6 . Additionally, TAK1 can activate p38, thus inducing EMT (52). Furthermore, the PI3K/Akt/mTOR pathway is involved in TGF- $\beta 1$ signal transduction. TGF- $\beta 11$ and TGF- $\beta 12$ are both involved in the activation of the PI3K pathway (53), and the induction of the TGF- $\beta 1$ receptor is suppressed by treatment with a PI3K inhibitor. Treatment with a TGF- $\beta 1$ inhibitor results in weakening of the TGF- $\beta 1$-mediated activation of PI3K and its effector molecule, Akt $(54,55)$. Taken together, these results indicated that TGF- $\beta 1$ is associated with MAPK and PI3K signaling pathways.

In the present study, western blot analysis indicated that treatment with astragaloside IV had an impact on pP38 in the MAPK signaling pathway; however, other proteins were not affected. Regarding the PI3K pathway, astragaloside IV treatment inhibited phosphorylation of PI3K, AKT, and mTOR to varying degrees. Thus, astragaloside IV inhibited both the MAPK and PI3K signaling pathways.

The MAPK and PI3K signaling mediators are widely present in the cytoplasm and nucleus of mammalian cells, and are involved in various physiological and pathological processes, including proliferation, autophagy, EMT and apoptosis of tumor cells (56-61). In the current study, treatment with astragaloside IV inhibited cervical cancer cells through these two pathways; however, whether this effect is associated with EMT remains unknown. To identify the therapeutic targets involved, inhibitors of the pathways were used, and the mRNA expression of E-cadherin, an EMT marker, was determined by RT-qPCR. The data revealed that E-cadherin expression was downregulated to varying extents after combination treatment with astragaloside IV and the pathway inhibitors. Based on these findings, it is inferred that both pathways are targets of the inhibitory effect of astragaloside IV on EMT in cervical cancer cells. However, a limitation of this study was that only a single cell line was used, and that further studies using other cell lines are required.

In this study, in vitro experiments demonstrated that astragaloside IV treatment inhibited EMT by inhibiting TGF- $\beta 1$, thus exerting an inhibitory effect on the invasion and migration of cervical cancer cells. However, plant extracts are affected by several factors inside the human body, including absorption, distribution, metabolism and secretion. To determine the in vivo effect of astragaloside IV treatment, tumor transplantation experiments with nude mice were performed. Tumor growth and metastasis were visualized by in vivo imaging, which demonstrated that treatment with astragaloside IV alone inhibited the metastatic ability of the cervical cancer cells. Notably, compared with the treatment with cisplatin alone, the combined use of astragaloside IV with cisplatin effectively prevented the metastasis of the cervical cancer cells.

In conclusion, astragaloside IV treatment reduced the invasive and migratory capacities of cervical cancer cells in vitro by inhibiting pP38 in the MAPK signaling pathway, and PI3K in the PI3K signaling pathway, while downregulating TGF- $\beta 1$ expression. These effects led to an increased level of the EMT marker, E-cadherin. Antitumor effects of astragaloside IV treatment were observed in vivo. Taken together, astragaloside IV is a natural active ingredient with low toxicity, and its combined use with cisplatin effectively prevented tumor growth and metastasis.

\section{Acknowledgements}

Not applicable.

\section{Funding}

The present study was supported by Key medical talent project in Jiangsu province (grant no. QNRC2016529) and Scientific Research Team of Jiangsu Health Vocational College (grant no. JKKYTD201703).

\section{Availability of data and materials}

The datasets used and analyzed during the current study are available from the corresponding author on reasonable request.

\section{Authors' contributions}

$\mathrm{CN}$ supervised and directed this study. LZ performed the majority of the experiments. $\mathrm{LZ}$ and $\mathrm{CN}$ contributed to the conception and design of the experiments. LZ and JZ contributed to the cell culture and RNA extraction. XQ and HH helped with interpretation of data. JZ analyzed the data and LZ wrote this manuscript. All authors read and approved the manuscript and agree to be accountable for all aspects of the research in ensuring that the accuracy or integrity of any part of the work are appropriately investigated and resolved.

\section{Ethics approval and consent to participate}

All animals were housed in a pathogen-free environment and fed ad libitum. The procedures for care and use of animals were approved by the Ethics Committee of the Jiangsu Health Vocational College (approval no. IACUC-201702) and all applicable institutional and governmental regulations concerning the ethical use of animals were followed.

\section{Patient consent for publication}

Not applicable.

\section{Competing interests}

The authors declare that they have no competing interests. 


\section{References}

1. Thaxton L and Waxman AG: Cervical cancer prevention: Immunization and screening 2015. Med Clin North Am 99: 469-477, 2015

2. Dappa E, Elger T, Hasenburg A, Düber C, Battista MJ and Hötker AM: The value of advanced MRI techniques in the assessment of cervical cancer: A review. Insights Imaging 8 471-481, 2017.

3. Campos NG, Burger EA, Sy S, Sharma M, Schiffman M, Rodriguez AC, Hildesheim A, Herrero R and Kim JJ: An updated natural history model of cervical cancer: Derivation of model parameters. Am J Epidemiol 180: 545-555, 2014.

4. Phillips P and Phillips J: Hysterectomy with radiotherapy or chemotherapy or both for women with locally advanced cervical cancer. Clin Nurse Spec 31: 189-190, 2017.

5. Ly A, Cheng HH and Alwan L: Hepatitis C infection and chemotherapy toxicity. J Oncol Pharm Pract 25: 474-480, 2019.

6. Wang YS, Tian J, Han Y, Han SM and Shi SB: Gemcitabine plus vinorelbine as second-line therapy in patients with metastatic esophageal cancer previously treated with platinum-based chemotherapy. Oncol Res 24: 129-135, 2016.

7. Majithia N, Temkin SM, Ruddy KJ, Beutler AS, Hershman DL and Loprinzi CL: National cancer institute-supported chemotherapy-induced peripheral neuropathy trials: Outcomes and lessons. Support Care Cancer 24: 1439-1447, 2016.

8. Momtazi-Borojeni AA, Ghasemi F, Hesari A, Majeed M, Caraglia $\mathrm{M}$ and Sahebkar A: Anti-cancer and radio-sensitizing effects of curcumin in nasopharyngeal carcinoma. Curr Pharm Des 24: 2121-2128, 2018.

9. Qing LS, Peng SL, Liang J and Ding LS: Astragalosidic acid: A new water-soluble derivative of astragaloside IV prepared using remarkably simple TEMPO-mediated oxidation. Molecules 22 E1275, 2017.

10. Yu WN, Sun LF and Yang H: Inhibitory effects of astragaloside IV on bleomycin-induced pulmonary fibrosis in rats via attenuation of oxidative stress and inflammation. Inflammation 39: $1835-1841,2016$

11. Li L, Hou X, Xu R, Liu C and Tu M: Research review on the pharmacological effects of astragaloside IV. Fundam Clin Pharmacol 31: 17-36, 2017.

12. Zhou X, Sun X, Gong X, Yang Y, Chen C, Shan G and Yao Q: Astragaloside IV from Astragalus membranaceus ameliorates rena interstitial fibrosis by inhibiting inflammation via TLR4/NF-кB in vivo and in vitro. Int Immunopharmacol 42: 18-24, 2017

13. Qiu L, Yin G, Cheng L, Fan Y, Xiao W, Yu G, Xing M, Jia R, Sun R, Ma X, et al: Astragaloside IV ameliorates acute pancreatitis in rats by inhibiting the activation of nuclear factor- $\kappa \mathrm{B}$. Int J Mol Med 35: 625-636, 2015.

14. Dai H, Jia G, Lu M, Liang C, Wang $\mathrm{Y}$ and Wang $\mathrm{H}$ Astragaloside IV inhibits isoprenaline-induced cardiac fibrosis by targeting the reactive oxygen species/mitogen-activated protein kinase signaling axis. Mol Med Rep 15: 1765-1770, 2017

15. Wang HL, Zhou QH, Xu MB, Zhou XL and Zheng GQ: Astragaloside IV for experimental focal cerebral ischemia: Preclinical evidence and possible mechanisms. Oxid Med Cell Longev 2017: 8424326, 2017.

16. Zhang L, Li Z, He W, Xu L, Wang J, Shi J and Sheng M Effects of astragaloside IV against the TGF- $\beta 11$-induced epithelial-to-mesenchymal transition in peritoneal mesothelial cells by promoting Smad 7 expression. Cell Physiol Biochem 37: 43-54, 2015.

17. Dai PC, Liu DL, Zhang L, Ye J, Wang Q, Zhang HW, Lin XH and Lai GX: Astragaloside IV sensitizes non-small cell lung cancer cells to gefitinib potentially via regulation of SIRT6. Tumour Biol 39: 1010428317697555, 2017.

18. Ye Q, Su L, Chen D, Zheng W and Liu Y: Astragaloside IV induced miR-134 expression reduces EMT and increases chemotherapeutic sensitivity by suppressing CREB1 signaling in colorectal cancer cell line SW-480. Cell Physiol Biochem 43: $1617-1626,2017$

19. Li B, Wang F, Liu N, Shen W and Huang T: Astragaloside IV inhibits progression of glioma via blocking MAPK/ERK signaling pathway. Biochem Biophys Res Commun 491: 98-103, 2017.

20. Zhang S, Tang D, Zang W, Yin G, Dai J, Sun YU, Yang Z, Hoffman RM and Guo X: Synergistic inhibitory effect of traditional chinese medicine astragaloside IV and curcumin on tumor growth and angiogenesis in an orthotopic nude-mouse model of human hepatocellular carcinoma. Anticancer Res 37: 465-473, 2017.
21. Liang G, Fang X, Yang Y and Song Y: Silencing of CEMIP suppresses Wnt $/ \beta$-catenin/Snail signaling transduction and inhibits EMT program of colorectal cancer cells. Acta Histochem 120: 56-63, 2018.

22. Zong W, Yu C, Wang P and Dong L: Overexpression of SASH1 inhibits TGF- $\beta 11$ induced EMT in gastric cancer cells. Oncol Res 24: 17-23, 2016.

23. Greenburg G and Hay ED: Epithelia suspended in collagen gels can lose polarity and express characteristics of migrating mesenchymal cells. J Cell Biol 95: 333-339, 1982.

24. Livak KJ and Schmittgen TD: Analysis of relative gene expression data using real-time quantitative PCR and the 2(-Delta Delta $\mathrm{C}(\mathrm{T})$ ) method. Methods 25: 402-408, 2001.

25. Gough W, Hulkower KI, Lynch R, McGlynn P, Uhlik M, Yan L and Lee JA: A quantitative, facile, and high-throughput image-based cell migration method is a robust alternative to the scratch assay. J Biomol Screen 16: 155-63, 2011.

26. Liang CC, Park AY and Guan JL: In vitro scratch assay: A convenient and inexpensive method for analysis of cell migration in vitro. Nat Protoc 2: 329-33, 2007.

27. Kovaříková P, Michalova E, Knopfová L and Bouchal P: Methods for studying tumor cell migration and invasiveness. Klin Onkol 27 (Suppl 1): S22-S27, 2014 (In Czech).

28. He AD, Wang SP, Xie W, Song W, Miao S, Yang RP, Zhu Y, Xiang JZ and Ming ZY: Platelet derived TGF- $\beta 1$ promotes cervical carcinoma cell growth by suppressing KLF6 expression. Oncotarget 8: 87174-87181, 2017.

29. Peng G, Masood K, Gantz O and Sinha U: Neuromuscular electrical stimulation improves radiation-induced fibrosis through TGF- $\beta 11 /$ MyoD homeostasis in head and neck cancer. J Surg Oncol 114: 27-31, 2016

30. Rhee YH, Moon JH, Choi SH and Ahn JC: Low-level laser therapy promoted aggressive proliferation and angiogenesis through decreasing of transforming Growth factor- $\beta 1$ and increasing of Akt/hypoxia inducible factor-1 $\alpha$ in anaplastic thyroid cancer. Photomed Laser Surg 34: 229-235, 2016.

31. Chen W, Zhou S, Mao L, Zhang H, Sun D, Zhang J, Li J and Tang JH: Crosstalk between TGF- $\beta 1$ signaling and miRNAs in breast cancer metastasis. Tumour Biol 37: 10011-10019, 2016.

32. Lin RL and Zhao LJ: Mechanistic basis and clinical relevance of the role of transforming growth factor- $\beta$ in cancer. Cancer Biol Med 12: 385-393, 2015.

33. Ma F, Li W, Liu C, Li W, Yu H, Lei B, Ren Y, Li Z, Pang D and Qian C: MiR-23a promotes TGF- $\beta 11$-induced EMT and tumor metastasis in breast cancer cells by directly targeting CDH1 and activating Wnt/ß-catenin signaling. Oncotarget 8: 69538-69550, 2017.

34. Lim WC, Kim H, Kim YJ, Choi KC, Lee IH, Lee KH, Kim MK and Ko H: Dioscin suppresses TGF- $\beta 11$-induced epithelial-mesenchymal transition and suppresses A549 lung cancer migration and invasion. Bioorg Med Chem Lett 27: 3342-3348, 2017.

35. Mitra T and Roy SS: Co-activation of TGF $\beta$ and Wnt signalling pathways abrogates EMT in ovarian cancer cells. Cell Physiol Biochem 41: 1336-1345, 2017.

36. Zhang JX, Zhai JF, Yang XT and Wang J: MicroRNA-132 inhibits migration, invasion and epithelial mesenchymal transition by regulating TGF $\beta 1 / \mathrm{Smad} 2$ in human non-small cell lung cancer. Eur Rev Med Pharmacol Sci 20: 3793-3801, 2016.

37. Zhang S, Sun WY, Wu JJ, Gu YJ and Wei W: Decreased expression of the type III TGF- $\beta 1$ receptor enhances metastasis and invasion in hepatocellullar carcinoma progression. Oncol Rep 35: 2373-2381, 2016

38. Zhu L, Fu X, Chen X, Han X and Dong P: M2 macrophages induce EMT through the TGF- $\beta 1 / \mathrm{Smad} 2$ signaling pathway. Cell Biol Int 41: 960-968, 2017.

39. Su S, Lin X, Ding N, Zhang H, Zhang Q, Ding Y, Hou X and Tian Y: Effects of PARP-1 inhibitor and ERK inhibitor on epithelial mesenchymal transitions of the ovarian cancer SKOV3 cells. Pharmacol Rep 68: 1225-1229, 2016.

40. Matos ML, Lapyckyj L, Rosso M, Besso MJ, Mencucci MV, Briggiler CI, Giustina S, Furlong LI and Vazquez-Levin MH: Identification of a novel human E-cadherin splice variant and assessment of its effects upon EMT-related events. J Cell Physiol 232: 1368-1386, 2017.

41. Benzina S, Beauregard AP, Guerrette R, Jean S, Faye MD, Laflamme M, Maïcas E, Crapoulet N, Ouellette RJ and Robichaud GA: Pax-5 is a potent regulator of E-cadherin and breast cancer malignant processes. Oncotarget 8: 12052-12066, 2017. 
42. Shin J, Song IS, Pak JH and Jang SW: Upregulation of annexin A1 expression by butyrate in human melanoma cells induces invasion by inhibiting E-cadherin expression. Tumour Biol 37: 14577-14584, 2016.

43. Zhang Z, Bu X, Chen $\mathrm{H}$, Wang $\mathrm{Q}$ and Sha W: Bmi-1 promotes the invasion and migration of colon cancer stem cells through the downregulation of E-cadherin. Int J Mol Med 38: 1199-207, 2016.

44. Singh R, Mandhani A, Agrawal V and Garg M: Positive correlation between matrix metalloproteinases and epithelial-to-mesenchymal transition and its association with clinical outcome in bladder cancer patients. Cancer Microenviron 11: 23-39, 2018.

45. Zheng QM, Chen XY, Bao QF, Yu J and Chen LH: ILK enhances migration and invasion abilities of human endometrial stromal cells by facilitating the epithelial-mesenchymal transition. Gynecol Endocrinol 34: 1091-1096, 2018.

46. Tang L, Dai F, Liu Y, Yu X, Huang C, Wang Y and Yao W: RhoA/ROCK signaling regulates smooth muscle phenotypic modulation and vascular remodeling via the JNK pathway and vimentin cytoskeleton. Pharmacol Res 133: 201-212, 2018.

47. Song IH, Kim KR, Lim S, Kim SH and Sung CO: Expression and prognostic significance of epithelial-mesenchymal transition-related markers and phenotype in serous ovarian cancer. Pathol Res Pract 214: 1564-1571, 2018.

48. Sokolova O, Kähne T, Bryan K and Naumann M: Interactome analysis of transforming growth factor- $\beta$-activated kinase 1 in Helicobacter pylori-infected cells revealed novel regulators tripartite motif 28 and CDC37. Oncotarget 9: 14366-14381, 2018.

49. Li H, He Q, Meng F, Feng X, Chen J, Li L and Liu J: Methionine sulfoxide reductase B1 regulates proliferation and invasion by affecting mitogen-activated protein kinase pathway and epithelial-mesenchymal transition in u2os cells. Biochem Biophys Res Commun 12: 806-813, 2018.

50. Liang Z, Wu R, Xie W, Zhu M, Xie C, Li X, Zhu J, Zhu W, $\mathrm{Wu}$ J, Geng S, et al: Curcumin reverses tobacco smoke-induced epithelial-mesenchymal transition by suppressing the MAPK pathway in the lungs of mice. Mol Med Rep 17: 2019-2025, 2018

51. Zhang C, Liu T, Wang G, Wang H, Che X, Gao X and Liu H: Rac3 regulates cell invasion, migration and EMT in lung adenocarcinoma through p38 MAPK pathway. J Cancer 8: 2511-2522, 2017.
52. Lu M, Chen WH, Wang CY, Mao CQ and Wang J: Reciprocal regulation of miR-1254 and c-Myc in oral squamous cell carcinoma suppresses EMT-mediated metastasis and tumor-initiating properties through MAPK signaling. Biochem Biophys Res Commun 484: 801-807, 2017.

53. Zhu Y, Kong F, Zhang C, Ma C, Xia H, Quan B and Cui H: CD133 mediates the TGF $\beta 1$-induced activation of the PI3K/ERK/P70S6K signaling pathway in gastric cancer cells. Oncol Lett 14: 7211-7216, 2017.

54. Saito S, Zhuang Y, Shan B, Danchuk S, Luo F, Korfei M, Guenther A and Lasky JA: Tubastatin ameliorates pulmonary fibrosis by targeting the TGF $\beta$-PI3K-Akt pathway. PLoS One 12: e0186615, 2017

55. Khan GJ, Gao Y, Gu M, Wang L, Khan S, Naeem F, Semukunzi H, Roy D, Yuan S and Sun L: TGF- $\beta 1$ causes EMT by regulating $\mathrm{N}$-Acetyl glucosaminyl transferases via downregulation of non muscle myosin II-A through JNK/P38/PI3K pathway in lung cancer. Curr Cancer Drug Targets 18: 209-219, 2018.

56. Nie C, Zhou J, Qin X, Shi X, Zeng Q, Liu J, Yan S and Zhang L: Diosgenin induced autophagy and apoptosis in a human prostate cancer cell line. Mol Med Rep 14: 4349-4359, 2016.

57. Nie C, Zhou J, Qin X, Shi X, Zeng Q, Liu J, Yan S and Zhang L: Reduction of apoptosis by proanthocyanidin-induced autophagy in the human gastric cancer cell line MGC-803. Oncol Rep 35: 649-658, 2016.

58. Wang R, Deng D, Shao N, Xu Y, Xue L, Peng Y, Liu Y and Zhi F: Evodiamine activates cellular apoptosis through suppressing PI3K/AKT and activating MAPK in glioma. Onco Targets Ther 11: 1183-1192, 2018.

59. Xia D, Tian S, Chen Z, Qin W and Liu Q: miR302a inhibits the proliferation of esophageal cancer cells through the MAPK and PI3K/Akt signaling pathways. Oncol Lett 15: 3937-3943, 2018.

60. Dinsmore CJ and Soriano P: MAPK and PI3K signaling: At the crossroads of neural crest development. Dev Biol pii: S0012-1606(17)30599-7, 2018.

61. Song ZY, Wang F, Cui SX and Qu XJ: Knockdown of CXCR4 inhibits CXCL12-induced angiogenesis in HUVECs through downregulation of the MAPK/ERK and PI3K/AKT and the Wnt/ $\beta$-catenin pathways. Cancer Invest 36: 10-18, 2018. 